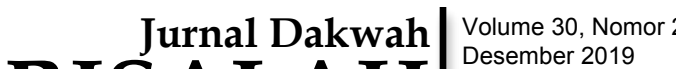 \\ RISALAH|
}

DOI: $10.24014 /$ jdr.v30i2.8492

\section{NILAI-NILAI ISLAM DALAM DRAMA KOREA PERSPEKTIF ANAK MUDA MUSLIM PEKANBARU}

\author{
Imron Rosidi ${ }^{1}$, Masduki ${ }^{2}$, Dony Arung Triantoro ${ }^{3}$ \\ ${ }^{1,2,3}$ Universitas Islam Negeri Sultan Syarif Kasim Riau \\ Email: imronrosidi@gmail.com
}

\section{Kata kunci}

Nilai Islam, Drama

Korea, Anak Muda

Muslim
Keywords

Islam Values, Korean TV Dramas, Muslim Youth

\section{Abstrak}

Artikel ini menjelaskan salah satu dampak globalisasi terhadap anak muda Muslim di Indonesia. Artikel ini berargumen bahwa munculnya globalisasi telah menyediakan kesempatan bagi anak muda Muslim untuk mengambil nilai-nilai 'Islami' dari dunia nonArab, tidak semata-mata dari pusat Islam (Negara-negara Arab Muslim). Tujuan dari penelitian ini untuk mengetahui bagaimana Anak Muda Muslim Pekanbaru mengambil nilai-nilai Islam yang terdapat dalam drama Korea. Penelitian ini menggunakan metode etnografi, dengan mengidentifikasi informan yakni anak muda Muslim Indonesia saleh dilihat dari latar belakang pendidikan Islam dan menyukai Drama televisi Korea. Mereka memiliki pemahaman Islam yang baik sehingga dalam kehidupan sehari-hari mereka biasa melakukan salat wajib sehari lima kali dan puasa wajib di bulan suci Ramadhan. Bahkan beberapa dari mereka melakukan ajaran-ajaran Islam yang bersifat sunnah seperti membaca Al-Qur'an, salat sunnah berjamaah di masjid dan lainnya. Artikel ini menemukan bahwa drama televisi Korea mendorong anak muda Muslim untuk menegoisasi nilai-nilai Islam yang ditampilkan dalam drama televisi Korea. Hasil penelitian ini mengungkapkan beberapa nilai-nilai Islam seperti aspek kerja keras, dan pantang menyerah sering digambarkan dalam drama televisi.

\section{Abstract}

This article describes one of the effects of globalization on young Muslims in Indonesia. This article argues that the emergence of globalization has provided opportunities for young Muslims to take 'Islamic' values from the non-Arab world, not solely from the center of Islam (Muslim Arab countries). The purpose of this study is to find out how Pekanbaru Muslim Youth take Islamic values contained in Korean drama. This research uses ethnographic methods, by identifying informants namely young Muslim Muslims who are pious from Islamic educational backgrounds and like Korean television dramas. They have a good understanding of Islam so that in daily life they used to do the obligatory prayers five times a day and fasting is obligatory in the holy month of 
Ramadan. Even some of them do the teachings of Islam that are sunnah such as reading the Qur'an, sunnah prayers in congregation in the mosque and others. This article found that Korean television dramas encourage Muslim young people to negotiate Islamic values displayed in Korean television dramas. The results of this study reveal some Islamic values such as aspects of hard work, and never give up are often portrayed in television dramas.

\section{Pendahuluan}

Popularitas drama Korea di Indonesia dipengaruhi oleh perkembangan pesat globalisasi media, dilihat dari mudahnya masyarakat mengakses produk-produk budaya dari negara lain melalui media mainstream. Oleh karena itu, proses perkembangan drama Korea di Indonesia dipengaruhi oleh popularitas drama korea di negara lain. Tidak heran jika popularitas drama Korea sebenarnya juga menghentak masyarakat lain, tidak semata-mata masyarakat Indonesia yang dikenal dengan istilah Korean Wave.

Istilah Korean Wave awalnya dikemukakan oleh media China dengan term atau istilah Hallyu. Pada tahun 1997, media-media China memberitakan popularitas Drama Korea yang berjudul "Star in My Heart". Drama Korea ini tidak hanya ditayangkan di China, namun juga di Taiwan, Hong Kong dan sejumlah negara-negara Asia lainnya. Baru-baru ini, istilah 'Korean Wave' menjadi isu yang banyak dibahas di sejumlah jurnal akademik, bahkan surat kabar dan blog-blog di Internet.

Kajian tentang drama Korea sangat melimpah dewasa ini. Chua Beng Huat (2008) misalnya mengkaji tentang elemen - elemen yang asing dalam tampilan drama Korea sebagai salah satu faktor penting penonton tertarik terhadap drama Korea. Namun studi yang dilakukan Rahmah Ida (2008) menunjukan bahwa konsep 'kedekatan budaya' cukup berperan mendorong popularitas drama Korea di Indonesia. Sang-Yeon Sung (2010) melihat dampak budaya pop Korea terhadap masyarakat Taiwan. Cho HaeJoang (2005) mengajukan pendapat bahwa drama Korea dan musik Korea menjadi basis popularitas Korean Pop culture (Budaya populer Korea) di dunia. Sejumlah penelitian tersebut tidak melihat adanya hubungan identitas penonton dan tayangan drama Korea. Padahal, dengan melihat itu, penelitian tentang drama Korea akan lebih bermanfaat sebab perspektif 'dari dalam' penonton pada hakekatnya juga berkontribusi terhadap popularitas drama Korea.

Penelitian ini menggunakan studi perspektif budaya, yang berkaitan dengan dampak globalisasi di kalangan umat Islam Indonesia di mana mereka telah berinteraksi dengan berbeda nilai-nilai dan norma-norma dari berbagai penjuru dunia. Dengan perhatian khusus diberikan kepada Indonesia, penelitian ini berpendapat bahwa kebangkitan globalisasi telah memberikan kesempatan bagi Muslim Indonesia untuk membuktikan bahwa mereka dapat mengambil nilai-nilai 'Islam' tidak hanya dari 'Arab' tetapi juga dari dunia 'non-Arab'. 
Globalisasi media telah mendukung bangkitnya multiplisitas Islam yang tidak hanya didominasi oleh Arab atau Timur Tengah.Dalam studi budaya, studi tentang globalisasi tidak dapat dipisahkan dengan masalah dominasi budaya tunggal (Tunstall dalam Tomlin Putra, 2008:8). Pada kenyataannya, Storey (2003) menolak itu karena sekarang ada banyak pusat-pusat kebudayaan di dunia. Dengan munculnya media global, arus budaya jamak yang mungkin datang dari negara mana pun. Oleh karena itu, artikel ini ingin mencari nilai-nilai Islam yang diambil dari Korea Selatan melalui produk budayanya oleh Anak Muda Muslim Indonesia. Seperti diketahui, Korea Selatan tidak memiliki banyak Muslim seperti Indonesia. Negara ini juga dikenal memiliki warisan Asia Timur yang berbeda dari kata Arab (Chua Beng Huat, 2015: 75-176). Ini berarti bahwa produk budayanya mencerminkan budaya Asia Timur daripada budaya Arab.

Akibatnya, sangat penting untuk bertanya kepada Anak Muda Muslim Indonesia yang dapat diidentifikasi sebagai 'saleh', mengapa mereka berinteraksi dan mengonsumsi produk budaya asing, dalam hal ini drama televisi Korea. Islam datang ke Indonesia melalui interaksi budaya oleh pedagang asing dan Sufi, jadi pertanyaan utama penelitian ini adalah sejauh mana drama televisi Korea sebagai produk budaya asing memperkaya dan menyebarkan nilai-nilai Islam di kalangan Anak Muda Muslim Indonesia. Penelitian ini bertujuan untuk mengetahui bagaimana Anak Muda Muslim Pekanbaru mengambil nilai-nilai Islam yang terdapat dalam drama Korea.

\section{Metode}

Secara metodologis, artikel ini menggunakan 'etnografi post-modern'. Kompleksitas tanggapan audiens terhadap pesan-pesan media telah mengarahkan sejumlah akademisi ke "etnografi" sehingga banyak peneliti telah melakukan studi etnografis tentang kejadian-kejadian tertentu dari konsumsi media dan menemukan pengetahuan yang terkait dengan proses tersebut (Milestone dan Meyer, 2012: 152). Dalam beberapa dekade terakhir, ada perhatian yang tumbuh untuk lebih fokus pada "yang lain" daripada "penulis" dalam melakukan etnografi. Hal ini disebut dengan "etnografi postmodern". "Yang lain" dalam hal ini mengacu pada "suara rakyat" daripada "suara penulis" (Ibrahim dan Noorshah, 2012). Sejak tahun 1970-an para akademisi telah mulai menyaring ide-ide post-modern ke dalam antropologi. Ini menandakan pentingnya "dialog" antara peneliti dan penduduk asli, bukan hanya berdasarkan" pemahaman peneliti (Fontana, 2004: 212).

Fontana mengkritik beberapa akademisi seperti Van Maanen yang berfokus pada suara penulis daripada suara asli. Postmodernis harus memperoleh validitas pada pelaporan etnografi dengan meminimalisasi suara penulis sehingga dapat dipercaya untuk fenomena dilaporkan. Fontana berpendapat bahwa "etnografer postmodern berupaya mendekonstruksi atau menghapus posisi dominan etnografer. Hal ini dilakukan bukan dengan membuat etnografer "menghilang" tetapi dengan 
menjadikannya "publik". Mengingat bahwa etnografer adalah bagian dari penelitian, untuk berbicara tentang "pemahaman" berdasarkan empati dengan penduduk asli memberi peneliti posisi istimewa."

Hal ini juga didukung oleh Linda T. Smith (1999: 2) yang mendorong penelitian yang berbasis pada perspektif masyarakat sebagai indvidu aktif. Menurut dia, para peneliti harus memberikan "tempat" bagi masyarakat tempatan untuk "meriwayatkan" dan "memberitahu" sehingga ada keseimbangan antara penulis dan masyarakat dalam penelitian mereka. Dia mengakui bahwa "masyarakat tempatan di seluruh dunia memiliki kisah lain untuk diceritakan yang tidak hanya mempertanyakan sifat yang diasumsikan dari cita-cita dan praktik-praktik yang mereka hasilkan, tetapi juga berfungsi untuk menceritakan kisah alternatif... "Ini tidak berarti bahwa peneliti seharusnya tidak memiliki pemahaman mereka tentang fenomena tetapi, menurut Fontana (2004: 214), bahwa "mereka berusaha untuk meminimalkan bias kepenulisan mereka dengan membiarkan penduduk asli berbicara sendiri sebanyak mungkin.“

Menggunakan teknik bola salju (Snow Ball) dalam mengumpulkan data, artikel ini memilih Muslim muda Indonesia yang suka mengkonsumsi drama TV Korea sebagai informan. Mereka diidentifikasi sebagai Muslim 'saleh' karena dari latar belakang pendidikan mereka telah dilatih di bawah lembaga pendidikan Islam. Pemahaman mereka tentang Islam juga tak terhitung diikuti dengan mempraktikkan ajaran Islam seperti salat harian dan puasa selama bulan Ramadhan. Bahkan, beberapa dari mereka melakukan 'sunnah' atau ajaran Islam opsional seperti membaca Al-Quran, salat setiap hari di masjid-masjid dan sebagainya.

Studi ini berfokus pada Anak Muda Muslim yang tinggal di Pekanbaru karena Pekanbaru sangat mempromosikan budaya Melayu yang identik dengan budaya Islam (Taufik, 2010). Tidak mengherankan bahwa umat Islam di Pekanbaru menghormati Muslim 'saleh' dan mereka umumnya memiliki aspirasi yang kuat terhadap nilai-nilai Islam yang berasal dari Timur Tengah. Beberapa penyebar terkenal di Pekanbaru memiliki latar belakang pendidikan dari negara-negara Arab seperti Mesir, Arab Saudi, Maroko, dan Sudan. Hal ini menunjukkan bahwa umat Islam di Pekanbaru terkait erat dengan nilai-nilai Islam yang berpusat dari Timur Tengah. Dengan demikian, menarik untuk mempelajari apakah kedatangan produk budaya dari Korea Selatan dapat menantang kesalehan Anak Muda Muslim di Pekanbaru atau bahkan berkontribusi terhadapnya.

Chua (2003: 5) menyatakan bahwa "secara umum, periode antara masa remaja dan pernikahan- periode yang secara umum dikenal sebagai 'masa muda', ketika seseorang termasuk dalam 'generasi muda'-adalah jendela untuk konsumsi tanpa batas untuk dan diri, dibatasi hanya oleh keadaan keuangan sendiri." Oleh karena itu, untuk mengidentifikasi cara mereka mengonsumsi drama televisi Korea di bawah kesulitan keuangan seperti itu diperlukan. Selain itu, ada "ketakutan" dalam masyarakat Muslim bahwa produk budaya asing dapat membahayakan identitas dan budaya Islam. Produk 
budaya asing dianggap sebagai produk "berbahaya" karena dapat menyebarkan nilainilai yang bertentangan nilai-nilai dan ajaran Islam. Selain itu, kajian tentang Anak Muda sangat penting untuk memahami dinamika sosial dan budaya kontemporer sebab sebagaimana dikatakan oleh Dolby dan Dimitriadis (2004: 4) bahwa Anak Muda adalah fokus penting untuk memahami dinamika sosial kontemporer. Mereka berada di garis depan menghadapi dan negosiasi mode baru transformasi teknologi dan manusia inti dari modernisasi.

Artikel ini menyakini posisi aktif Anak Muda dan bukan 'penerima pasif budaya'. Dalam studi budaya, konsumsi budaya dianggap sebagai konsumsi kreatifsebagaimana dinyatakan oleh Chris Barker (2000:46). Hal ini berarti bahwa "makna" yang diterima oleh khalayak tidak dimonopoli oleh Produser atau orang-orang yang membuat pesan. Konsumen atau khalayak aktif menafsirkan makna yang dikirim karena teks yang diedarkan oleh produsen adalah "polisemik". Produk budaya seperti musik, film, dan televisi diproduksi oleh perusahaan "kapitalis" tapi makna selalu diperebutkan oleh konsumen atau khalayak. Audiens memiliki kemampuan untuk selektif terhadap makna yang dikirim. Peran aktif dari konsumen dalam negosiasi "makna" yang dikirim oleh teks-teks budaya berkontribusi untuk keterlibatan konsumen dan teks budaya dalam praktek. Goodman dan Cohen (2004: 2) mengemukakan bahwa konsumsi bukan sekadar perolehan makna produk yang telah ditentukan sebelumnya. Konsumsi bukanlah proses satu arah tetapi proses negosiasi dan kontestasi.

Oleh karena itu, penelitian ini menekankan bahwa Anak Muda adalah konsumen aktif drama TV Korea. Hal ini menandakan bahwa komentar dan pendapat mereka tentang drama TV Korea sangat penting dalam penelitian ini untuk memberikan temuan penelitian.

\section{Hasil dan pembahasan \\ Belajar Nilai-Nilai}

Bagi sebagian besar Muslim di Indonesia, memberikan pemahaman yang baik tentang Islam biasanya dimulai dari keluarga (orang tua) dan lembaga pendidikan. Keluarga, terutama orang tua, biasanya melatih pemahaman dasar tentang nilai-nilai Islam sementara lembaga pendidikan baik formal maupun informal melatih tingkat ajaran yang lebih maju. Aan, (25 tahun), mengatakan:

"Sebelum melanjutkan studi di universitas, saya menghadiri dan lulus dari sekolah-sekolah Islam, yaitu sekolah dasar Islam atau 'Madrasah Ibtidaiyah', sekolah menengah pertama Islam atau 'Madrasah Tsanawiyah', dan sekolah menengah Islam atau 'Madrasah Aliyah'. Madrasah Aliyah yang saya hadiri adalah sebuah pesantren yang jauh dari rumah. Karena itu, ketika saya melanjutkan studi di universitas di sini, saya merasa tidak nyaman harus tinggal jauh dari orang tua saya. Selain sekolah, saya juga dididik oleh orang tua saya untuk menjadi Muslim yang saleh di rumah. Ayah saya selalu mengendalikan 
saya untuk disiplin dalam melaksanakan sholat harian dan ajaran Islam lainnya. Saya ingat ketika saya berusia sepuluh tahun, orang tua saya memaksa saya untuk melakukan doa sehari-hari dengan baik; inilah cara saya diajari untuk menjadi seorang Muslim yang saleh. Pada bulan Ramadhan, saya diperintahkan oleh ayah saya untuk berpuasa, karena wajib bagi umat Islam untuk merayakan puasa sepanjang bulan. Ketika saya bisa menyelesaikan puasa sebulan penuh, ayah saya akan menghargai saya. Padahal, baik ayah dan ibu saya hanya lulusan sekolah dasar. Tetapi mereka memastikan saya menerima pendidikan Islam formal melalui institusi pendidikan, dan juga secara informal di rumah."

Dari latar belakang pendidikan Aan, dapat diidentifikasi bahwa ia telah dilatih di bawah lembaga pendidikan Islam. Orang tuanya juga memberinya ajaran Islam dan nilai-nilai di rumah. Namun, itu tidak cukup baginya. Ketika dia belajar di Universitas Islam Negeri, dia mulai tahu tentang Hizbut Thahrir. Dia lebih intensif mencari di internet tentang organisasi ini. Dia mulai mendapatkan informasi tentang nilai-nilai Islam dari sumber digital.

Aan lebih lanjut berkata:

"Saya mengidolakan Hizbut Tahrir Indonesia, sebuah organisasi Islam yang berupaya mendirikan 'Khilafah Islamiyah' di negara-negara Asia Tenggara. Interaksi saya dengan organisasi ini telah didukung dengan mengakses informasi dan propagandanya di internet."

Internet telah memberi kaum muda Muslim informasi aksesi tentang ajaran dan nilai-nilai Islam. Media baru ini kemudian dapat disebut sebagai sumber digital bagi Anak Muda Muslim untuk belajar nilai-nilai Islam. Hal ini menunjukan bahwa sumber digital telah menggeser peran otoritas dan sumber utama dalam mendefinisikan dan menginformasikan tentang nilai-nilai Islam.Tidak heran jika baru-baru ini sebagian besar Anak Muda Muslim lebih mudah berinteraksi dengan internet daripada sumbersumber 'umum' seperti Ulama, guru, dan orang tua. Dengan satu klik dalam beberapa detik, mereka dapat memperoleh informasi tentang nilai-nilai yang ingin mereka ketahui.

Cita-cita Aan terhadap Hizbut Tahrir telah ditantang oleh konsumsi baru-baru ini yang ia lakukan terhadap drama TV Korea. Sebagai sumber baru, drama TV Korea adalah produk budaya yang sebagian besar menggambarkan tayangan atau tampilantampilan dan gagasan modernitas dan kisah cinta. Ini tentu saja menantang identitas utamanya sebagai individu Muslim karena mereka diproduksi di masyarakat nonMuslim. Untuk waktu yang lama, ia telah melatih ajaran-ajaran Islam dan nilai-nilai dari sumber-sumber utama Islam tetapi dengan munculnya media global ia juga telah belajar tentang nilai-nilaidari sumber-sumber baru seperti internet dan drama televisi Korea.

Dengan munculnya sumber-sumber yang baru ini sebagai dampak dari globalisasi, hal ini menunjukkan bahwa ada banyak 'pusat' belajar tentang nilai-nilai Islam untuk kaum muda Muslim di Pekanbaru. Namun, dalam sumber-sumber baru ini, 
ada juga banyak elemen budaya dan nilai-nilai non-Islam yang ditunjukan. Di internet, selain situs-situs yang menampilkan nilai-nilai Islam, ada banyak situs porno yang bertentangan dengan ajaran dan identitas utama Anak Muda Islam ini.

\section{Belajar Nilai-Nilai Islam Dari Drama Korea}

Sejumlah informan mengakui bahwa mereka banyak belajar nilai-nilai Islam dari drama televisi korea. Zul, misalnya, mengidentifikasi bahwa semangat perjuangan yang diwakili dalam drama televisi Korea memotivasi dia untuk melakukan hal yang sama. Dia belajar dari drama televisi Korea di mana karakter mereka mempromosikan istilah "fighting". Istilah ini biasanya merujuk pada situasi ketika satu karakter dalam drama televisi Korea ingin membangkitkan semangat mereka untuk berjuang untuk mencapai keinginan dan impian mereka. Ketika Zul merasa bahwa dia perlu banyak upaya untuk menyelesaikan beberapa tugas yang diberikan oleh dosennya, dia tidak mau menyerah. Untuk mengungkapkan perasaannya, ia memperbarui status Facebooknya pada 18 Juni 2014 dengan kata "fighting". Status ini terkait erat dengan perasaannya yang ingin menyelesaikan tugasnya yang diberikan oleh dosennya meskipun ia memiliki jadwal kegiatan yang padat. Selain belajar, Zul mengajar di sebuah sekolah dasar di Pekanbaru untuk mendukung biaya hidupnya. Dia mengakui bahwa dia memahami istilah "fighting" secara kontekstual setelah mengkonsumsi drama televisi Korea.

Informan lain, Selly, menganggap bahwa drama televisi Korea untuk sementara dapat menyegarkan pikirannya dari masalah yang dia hadapi dalam kehidupan seharihari. Drama-drama televisi Korea di samping memberinya kesenangan yang jarang ia temukan dalam kehidupan sehari-harinya sebagai seorang mahasiswa di Pekanbaru, ia juga menyediakan sejumlah nilai-nilai moral yang Islam. Karena itu, melalui drama televisi Korea, dia bisa terlibat dalam sesuatu yang menyenangkan sekaligus 'belajar'. Selly mengekspresikan:

"Saya pikir drama televisi Korea dapat menyegarkan pikiran saya. Terkadang, saya mencari sesuatu yang menghibur setelah mempelajari banyak hal yang membuat saya stres. Ketika saya menonton drama televisi Korea, saya merasa segar karena ketika saya menonton sesuatu yang lucu saya bisa tertawa dan terbebas dari beban apa pun. Apalagi kalau saya perhatikan dalam drama korea ada beberapa adegan yang mana Anak Muda bersikap hormat terhadap yang lebih tua, misalnya bapaknya atau ibunya."

Oleh karena itu, walaupun drama televisi Korea telah menyediakan dunia yang tidak nyata, dia setuju bahwa produk budaya Korea ini mampu memberikan kenyamanan sesaat dari tekanan kehidupan sehari-harinya. Selain itu, untuk informan lain, drama televisi Korea memberikan Anak Muda Indonesia memimpikan anak lakilaki yang keren dan imut. Ini dapat menyegarkan kembali kaum muda setelah mengalami masalah di sekolah, universitas atau di tempat kerja. Namun bahasa atau 
istilah 'imut' dan 'keren' tetap harus berkompromi dengan nilai-nilai lain yang mereka pelajari sejak kecil.

Anak muda lain menganggap bahwa drama televisi Korea sangat berharga karena drama ini mampu menghasilkan dan menciptakan karakter pria dan wanita yang kuat. Karakter-karakter ini dapat digunakan sebagai referensi penting dalam interaksi sehari-harinya. Karakter-karakter ini sebagian besar diidentifikasi kuat karena mereka berjuang keras untuk mencapai ambisi mereka. Ketika mereka jatuh cinta dengan gadisgadis itu, mereka akan bekerja keras untuk mendapatkannya. Madan berkata:

"Saya suka drama televisi Korea karena karakter utama mereka memberikan contoh terbaik tentang bagaimana menjadi pria yang kuat dalam hidup. Mereka terkadang membuat saya merenungkan diri sendiri. Mereka juga menunjukkan bahwa dalam kondisi tertentu saya harus percaya diri."

Komentar di atas menandakan bahwa ada beberapa nilai moral yang digambarkan dalam drama televisi Korea yang mungkin tidak diperoleh dalam pendidikan formal mereka, dan dapat digunakan oleh audiens mereka dalam menangani masalah sehari-hari. Interpretasi ini relevan karena sebagian besar karakter, baik lakilaki maupun perempuan, dalam drama televisi Korea menunjukkan kepribadian mereka yang kuat dalam berusaha mencapai tujuan mereka. Oleh karena itu, dapat diterima ketika Dorothy Hobson (2005: 604) menyatakan bahwa pada dasarnya serial televisi seperti drama televisi Korea berhubungan dengan kehidupan sehari-hari.

Anak muda muslim di Pekanbaru bersifat heterogen dalam hal asal dan latar belakang mereka. Mereka bisa dari Jawa atau desa-desa terpencil di daerah terdalam di provinsi Riau. Riau sebagai provinsi di Pulau Sumatera terdiri dari banyak desa yang terkadang tidak tersentuh oleh pembangunan pemerintah. Desa Madani misalnya adalah contoh terbaik. Lokasinya jauh dari Pekanbaru. Listrik baru tiba di desa ini dua tahun yang lalu (pada saat penulisan). Hamdah, yang merupakan salah satu informan dalam penelitian ini berasal dari desa ini, dan telah bermigrasi ke Pekanbaru. Dia datang ke Pekanbaru untuk mencari uang dan berinteraksi dengan modernitas. Pekanbaru baginya adalah tempat terbaik di Riau untuk belajar nilai-nilai Islam yang kompatibel dengan modernitas. Tak heran jika unculnya drama televisi Korea telah menyumbang pengetahuan kepada Anak Muda Muslim yang menontonnya tentang nilai kebersihan. Fitri mengatakan:

"Terkadang, saya membayangkan kapan Indonesia bisa seperti itu. Dalam drama televisi Korea, saya melihat bahwa lingkungan di Korea bersih, tidak ada sampah. Rumah mereka modern. Jalanan bagus dan tidak ada sampah di jalan. Saya pikir Indonesia harus melihat Korea agar menjadi modern di masa depan." Para anak muda ini mampu mengambil beberapa nilai Islam yang terwakili dalam drama televisi yang mungkin tidak mereka temukan dalam pendidikan formal mereka. Misalnya, mereka belajar menjadi pekerja keras. Seperti halnya yang tertuang 
pada kitab suci Al-Qur'an, Nilai mengenai kerja keras juga dijelaskan dalam surah AtTaubah Ayat 105 yang berbunyi:

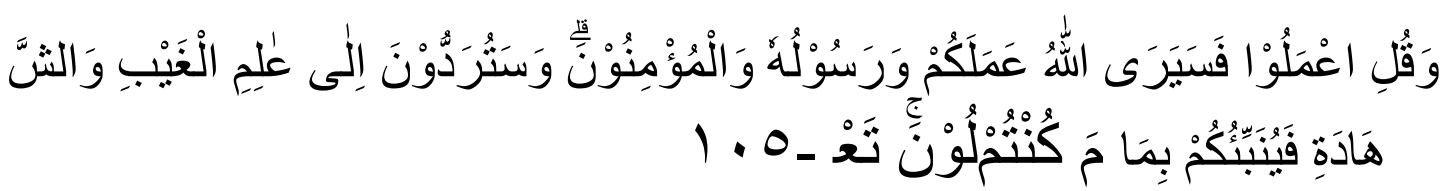

Artinya: Dan katakanlah, "Bekerjalah kamu, maka Allah akan melihat pekerjaanmu, begitu juga Rasul-Nya dan orang-orang mukmin, dan kamu akan dikembalikan kepada (Allah) Yang Mengetahui yang gaib dan yang nyata, lalu diberitakan-Nya kepada kamu apa yang telah kamu kerjakan." (At-Taubah-Qur'an Kemenag, 2020)

Mereka juga memiliki kemampuan untuk menentang beberapa nilai negatif yang bertentangan dengan identitas dan budaya mereka. Mereka adalah konsumen aktif yang dapat meninggalkan nilai-nilai negatif yang terlihat di drama. Melalui drama televisi Korea sebagai salah satu produk budaya transnasional yang dikonsumsi oleh Anak Muda Indonesia, mereka dapat "menjelajahi berbagai hal di luar sekolah karena kehidupan bukan hanya tentang hitam dan putih, tetapi ada beberapa area abu-abu yang perlu dijelajahi" (Zawawi: 2009). Anak muda muslim Indonesia memiliki identitas budaya bawaan serta pengetahuan sadar, yang telah mereka peroleh dari lingkungan belajar mereka (misalnya pendidikan) dan budaya. Para akademisi menyebut ini sebagai audiens aktif. Dalam hal ini, Paul Willis (1998: 550) menyatakan bahwa konsumerisme sekarang harus dipahami sebagai proses yang aktif, bukan pasif.

Anak Muda Muslim menafsirkan "cerita" dalam drama dengan menghubungkannya dengan pengalaman sehari-hari mereka. Beberapa kisah yang menggambarkan pergulatan hidup bersifat langsung dan Islam bagi mereka. Hal ini dikarenakan mereka juga berjuang untuk memiliki masa depan yang lebih baik dalam hidup. Beberapa dari mereka masih belajar di sekolah atau universitas, sementara yang lain sedang berjuang untuk mendapatkan pekerjaan. Dalam drama televisi Korea, perasaan hubungan keluarga yang kuat sering digambarkan, dan ini adalah sesuatu yang berkorelasi dengan nilai-nilai Islam.

Ini berarti bahwa kemungkinan produk budaya transnasional dalam menyebarkan nilai-nilai "Islam" dapat terjadi. Ada adegan-adegan tertentu yang digambarkan dalam drama televisi Korea yang dapat memberikan nilai-nilai Islam bagi Anak Muda Muslim Indonesia. Ini karena kaum muda Muslim selalu menegosiasikan representasi yang ditampilkan oleh media termasuk dalam hal ini drama televisi Korea. Melalui drama televisi Korea, mereka mengakui bahwa mereka mempelajari beberapa nilai-nilai Islam seperti aspek kerja keras, yang sering digambarkan dalam drama televisi. Menjadi muslim muda yang taat di satu sisi dan menjadi sukses dalam karier mereka di masa depan adalah cita-cita utama mereka yang membutuhkan kerja keras. 
Belajar dari drama televisi Korea, anak-Anak Muda telah memahami bahwa untuk menjadi individu yang berhasil, seseorang tidak boleh pantang menyerah dan putus asa.

\section{Simpulan}

Selama mengkonsumsi drama televisi Korea, Anak Muda Muslim di Pekanbaru mampu menegosiasikan dan memperebutkan nilai-nilai yang mereka sebut sebagai nilai-nilai Islam dari drama televisi. Hal ini berarti bahwa popularitas budaya pop Korea yang muncul adalah medan perjuangan dan negosiasi antara penonton dan produser.

Lebih lanjut, studi ini menunjukkan bahwa Anak Muda Muslim di Indonesia tidak secara pasif menerima semua pesan yang disampaikan oleh media seperti drama televisi Korea. Saat menonton drama televisi Korea, anak-anak muda Muslim ini mampu mengidentifikasi unsur-unsur Islam yang dekat dengan identitas dan budaya mereka. Hal ini menjadi salah satu dasar yang membuat mereka tertarik mengkonsumsi drama televisi ini. Pada hakekatnya, representasi drama televisi Korea selalu dinegosiasikan dan diperebutkan karena Anak Muda Muslim Indonesia juga percaya bahwa drama televisi Korea tidak sepenuhnya kompatibel dengan identitas dan budaya mereka. Namun demikian, salah satu dampak penting yang ditemukan dalam artikel ini adalah mereka meyakini bahwa, untuk menjadi modern tetapi saleh, bisa belajar dari berbagai sumber. Salah satunya adalah dengan mempelajari nilai-nilai Islam melalui drama televisi korea yang mereka sukai.

\section{Referensi}

Ang, Ien. (2006). Living Room Wars: Rethinking Media Audience for a Post-Modern World. London: Routledge.

Appadurai, Arjun. (1998). Modernity at Large: Cultural Dimensions of Globalization, Minneapolis: University of Minnesota Press.

At-Taubah-Qur'an Kemenag. (2020). http://quran.kemenag.go.id/index.php/sura/9

Barker, Chris. (2000). Cultural Studies: Theory and Practice. London: SAGE Publications.

Cho Hae-Joang. (2005). "Reading the Korean Wave as a Sign of Global Shift" in Korea Journal, Winter: 150

Chua Beng Huat. (2015). "Korean Pop Culture: Emergent Genre of East Asian Pop Culture?" in The Korean Wave in Southeast Asia: Consumption and Cultural Production, ed. Mary J. Ainslie and Joanne B.Y. Lim. Petaling Jaya: SIRD.

Chua Beng Huat. (2008). "Structure of Identification and Distancing in Watching East Asian Television Drama" in East Asian TV Dramas: Analysing the Korean Wave, ed. Chua Beng Huat and Koichi Iwabuchi, Hong Kong:Hong Kong University Press 
Chua Beng Huat. (2003). Life is Not Complete Without Shopping: Consumption Culture in Singapore. Singapore: Singapore University Press, 2003.

Dolby, Nadine and Greg Dimitriadis, eds., (2004). Learning to Labor in New Times. London: Routledge.

Do Kyun Kim et al., "Television Drama, Narrative Engagement and Audience Buying Behavior: The Effects of Winter Sonata in Japan," The International Communication Gazette 71, no. 7 (2009): 578.

Fontana, Andrea. (2004). "Ethnographic Trends in the Postmodern Era," in Postmodernism and Social Inquiry, ed. David R. Dickens and Andrea Fontana . London: University College London, 2004

Friedman, Jonathan. (1994). "Globalization and Localization," in Cultural Identity and Global Process. London: SAGE Publications.

Hall, Stuart, Paddy Whannel. (1998). "The Young Audience," in Cultural Theory and Popular Culture: A Reader, ed. John Storey, London: Prentice Hall.

Hobson, Dorothy. (2005). "Everything Stops for Crossroads," in Media Studies: A Reader, ed. Paul Marris and Sue Thornham. Edinburgh: Edinburgh University Press.

Ida, Rahmah. (2008). "Consuming Taiwanese Boys Culture : Watching Meteor Garden with Urban Kampung Women", in Popular Culture in Indonesia : Fluid Identities in Post-Authoritarian politics, ed. Ariel Heryanto, London : Rotledge.

Qialoei Jiang and Louis Leung, "Lifestyles, Gratification Sought, and Narrative Appeal: American and Korean TV Drama Viewing Among Internet Users in Urban China," The International Communication Gazette 74, no. 2 (2012): 161.

J. Goodman, Douglas, Mirelle Cohen. (2004). Consumer Culture: A Reference Handbook. California: ABC-CLIO. Inc.

Jonghoe Yang, "The Korean Wave (Hallyu) in East Asia: A Comparison of Chinese, Japanese, and Taiwanese Audiences who Watch Korean TV Dramas," Development and Society 41, no. 1 (2012): 110-11.

Milestone, Katie, Anneke Meyer. (2012). Gender and Popular Culture. New York: Polity Press, 2012.

Storey, John. (2003). Cultural Studies and the Study of Popular Culture. Edinburgh: Edinburgh University Press.

Sang-Yeon Sung. (2010).“Constructing a New Image: A Hallyu in Taiwan”, in European Journal of East Asian Studies 9.1 (2010): 25-45

Taufik Ikram Jamil, Membangun Ingatan; Sebuah Abstraksi, Paper presented on Seminar Nasional Bahasa Indonesia in Pekanbaru 21-23 December 2010

Tomlinson, John. (2001). Cultural Imperialism. London: Continuum.

Tuhiwai Smith, Linda. (1999). Decolonizing Methodologies: Research and Indigenous Peoples (London: Zed Books Ltd. 
Willis, Paul (1998) "Symbolic Creativity," in Cultural Theory and Popular Culture: A Reader, ed. John Storey. London: Prentice Hall.

Zawawi Ibrahim and Noorshah M.S., (2012) "Memperkenalkan Naratif Keterpinggiran dan Jatidiri Penan: Satu Wacana Postmodernis," in Masyarakat Penan dan Impian Pembangunan: Satu Himpunan Naratif Keterpinggiran dan Jatidiri, ed. Zawawi Ibrahim and Noorshah M.S. Petaling Jaya: SIRD.

Zawawi Ibrahim. (2009). “The 'other' Education: Exploring Agency and Youth Culture in Malaysia" (presentation at Redesigning Pedagogy International Conference, Panel: Popular Culture and Education in Asia National Institute of Education, Nanyang Technological University, Singapore, 1-3 June). 